\title{
LEIBNIZ E ARNAULD - ENTENDIMENTO E CONSENSO: A LÍNGUA E A LÓGICA DOS MODERNOS
}

\author{
Humberto Guido* \\ Ao amigo Paulo Roberto Ribeiro da Silva
}

\section{RESUMO}

O grande século da Filosofia Moderna é lembrado quando se evoca os seus protagonistas: Descartes, Locke, Espinosa. Contudo, outros pensadores estiveram empenhados não apenas na formulação das ideias basilares da nova filosofia; eles se propuseram a tarefa da crítica da filosofia do grande século, da qual eles também eram os protagonistas. Certamente esta atitude reserva lugar proeminente na História da Filosofia a dois pensadores: Arnauld e Leibniz, cujo diálogo epistolar é o tema para a reflexão sobre o racionalismo moderno.

Palavras-chave: História da Filosofia. Filosofia Moderna. Leibniz. Arnauld.

\begin{abstract}
The great century of Modern Philosophy is brought to mind when calling on its main characters: Descartes, Locke, Spinoza. However, other thinkers were engaged not only in formulating the basic ideas of the new philosophy, but they proposed to undertake the critique of the philosophy of this great century of which they were also the protagonists. This attitude certainly reserves a prominent place in the History of Philosophy for these two

\footnotetext{
${ }^{*}$ Professor Associado do Instituto de Filosofia da Universidade Federal de Uberlândia. Este artigo contou com o apoio do CNPq. E-mail: guido@ufu.br
} 
thinkers: Arnauld and Leibniz, whose epistolary dialogue is the theme for reflection on modern rationalism.

Keywords: History of Philosophy. Modern Philosophy. Leibniz. Arnauld.

O grande século demanda outras leituras. Um bom contraponto ao século de Luis XIV foi o movimento filosófico-pedagógico de PortRoyal. Esta afirmação foi feita por Gérard Lebrun:

Quando for visitar os esplendores de Versalhes, tenha um pensamento para o vale de Port-Royal, que se encontra a alguns quilômetros. Inútil, todavia, ir até lá. Você encontrará apenas alguns traços de alicerces, invadidos pelo mato. Aqui nada de escadarias de mármore ou jatos d'água: não há nem mesmo pedra sobre pedra para nos lembrar que viveram nestes lugares Arnauld e os Messieurs, Pascal e Jacqueline, a madre Angélica e Racine adolescente. Assim é. Raramente o "Estado Moderno" pisoteou tão insolentemente uma cultura. ${ }^{1}$

A majestade do tempo não se limitou ao recesso da realeza, espargiu seu fascínio sobre as ciências e as artes, servindo-se da melhor filosofia em sua versão oficial. O movimento de afirmação da nova mentalidade não foi isento de violência, algo tido como tolerável, porque era preciso, a qualquer custo, assentar a ciência moderna no panteão da humanidade, expulsando de lá as pretensas crenças racionais que se valiam de outras razões que não o more geométrico. Os nomes mencionados por Lebrun, e também o do filósofo alemão que comparece no título desta intervenção, não ficaram à margem do movimento de renovação da cultura científica, contudo, não se sujeitaram à despersonalização da prática científica.

O resgate de outras personagens do grande século, além daquelas consagradas pela história oficial da filosofia, é uma tentativa de reconhecimento da vitalidade da modernidade. No andamento do grande

${ }^{1}$ LEBRUN, 1983, p. 63. 
século a harmonia e o equilíbrio entre a experiência espiritual e a prática da ciência, cujo escopo era a renovação do humanismo, foi suplantado pelo movimento hegemônico da cultura moderna, que no lugar do humanismo erigiu o individualismo como referência para as relações sociais. Essa mudança de rumo decorreu de ordens externas impostas pela economia política, que vieram restringir a abertura para o mundo, produto daquela antropologia, que rapidamente perdeu espaço para o historicismo, cujos adeptos valiam-se do expediente teleológico para promover o governo absoluto da razão como Estado ideal para os negócios humanos.

Apesar do aparente triunfo da razão dialética é preciso pensar o grande século sem omitir as personagens mencionadas por Lebrun; a elas é preciso incluir o nome de Leibniz, que foi correspondente de Arnauld e com ele sustentou uma fecunda discussão filosófica sobre as polêmicas religiosas do período. Tais discussões não se limitavam às disputas teológicas tão em moda, no lugar da erudição eclesiástica, os temas tratados pelos filósofos em questão estavam diretamente ligados às novas concepções de homem e de mundo. Certamente Leibnizé figura notória da evolução do pensamento moderno, contudo, a sua contribuição significativa não está apenas na formulação do cálculo infinitesimal ou nos Novos ensaios acerca do entendimento humano; a Teodicéia, a Monadologia, entre outros escritos afins, merecem igual atenção. Leibniz, Arnauld e seus companheiros de Port-Royal, durante o século XVII, foram mais que melhores matemáticos, ou filósofos, ou astrônomos, ou advogados; naquele século esses homens foram distinguidos por Pascal, que os viam como indivíduos universais, ${ }^{2}$ pessoas que se aproximavam daquilo que se pode definir por homem de bem, o honnête homme. ${ }^{3}$

\footnotetext{
${ }^{2}$ A nomenclatura de Pascal é semelhante àquela que é encontrada na Filosofia da História (1995) de Hegel, em seu compêndio, o filósofo alemão se reporta aos indivíduos históricos universais, no entanto a proximidade é apenas semântica, pois Pascal vislumbra os homens de bem, Hegel por seu turno vislumbra os ícones da história universal: Alexandre, César e Napoleão Bonaparte.
}

${ }^{3}$ PASCAL, 1988, p. 45, $\S 35$. 
Os homens de bem dão a dimensão da condição existencial que não se adéqua à definição humanista de homem, nem à tendência individualista do liberalismo nascente, e que passou a ser predominante a partir dos séculos subsequentes. Arnauld e Leibniz ilustram a categoria antropológica concebida por Pascal. Eles foram homens de ação, estiveram imbuídos no aprimoramento do comportamento humano, de maneira que as suas ideias não estiveram em momento algum divorciadas da esfera da vida comum.

Arnauld teve sua vida ligada à Port-Royal. Naquele lugar ele encontrou o refúgio para se subtrair à perseguição religiosa, aproveitando a estadia para a concretização do ideal pedagógico que pretendia oferecer não apenas a melhor educação escolar, mas também disseminar a moral raciocinada que poderia trazer a estabilidade tão necessária para a sociedade sacudida pelas guerras, civis e religiosas, todas causadas pela intolerância. Somente a boa educação poderia orientar o entendimento e purgar o coração dos males sociais. A experiência pedagógica de PortRoyal chama a atenção, pois se tratava de um movimento pedagógico de pequena dimensão, ${ }^{4}$ contudo, a repressão aplicada às Escolinhas foi violenta e de grande repercussão. É provável que o zelo pedagógico e o rigor filosófico causavam insegurança nas autoridades civis e eclesiásticas, atentas para o que poderia ganhar vulto com as iniciativas educacionais que não separavam a elaboração teórica da prática efetiva do pensamento científico. A capacidade aglutinadora de Arnauld tornou possível não apenas o funcionamento das Escolinhas, contribuiu para a elaboração de livros destinados aos mestres e aos alunos, levando aos bancos escolares a nova filosofia, introduzindo as descobertas do grande século na ordem do dia, na esfera da vida comum.

\footnotetext{
${ }^{4}$ Bassetto e Murachco corroboram esta afirmação: "No período áureo de funcionamento dessas Escolinhas todas, chegaram a ter cerca de 50 alunos, sem dúvida um número quantitativamente pequeno, mas de excepcional qualidade, tanto em relação ao corpo docente como ao discente, como se pode comprovar pelo número e valor de obras produzidas”. (BASSETTO; MURACHCO, 1992, p. 22).
} 
Outro mérito de Arnauld foi o de ser interlocutor dos melhores pensadores da época, especialmente Descartes e Leibniz; a correspondência desses filósofos fazem as vezes de apêndices às suas elaborações teóricas. Neste momento merece atenção a correspondência mantida entre Arnauld e Leibniz. Nessas cartas, a filosofia cartesiana serviu de pano de fundo, trazendo para o debate os temas candentes daquele período. A distinção do corpo e da alma e a bondade de Deus, por exemplo, serviram de fundamento para a ciência e a moral modernas, ao menos foi esta a convicção de Arnauld e Leibniz.

Além da prolixidade, as cartas traziam a resenha das atividades empreendidas pelos autores. Em uma dessas cartas de Leibniz a Arnauld, datada de 14 de julho de 1686, o filósofo alemão relata as suas ocupações:

Tenho feito várias reflexões sobre a Jurisprudência, e me parece que poderei estabelecer alguma coisa de sólido e de útil; [...].

Tenho estado curioso também em matéria de minas [...] e acredito ter feito algumas descobertas sobre a geração, não tanto dos metais, mas da forma em que são encontrados, [...].

Além disso, tenho reunido em minhas mãos as memórias e os títulos concernentes à história de Brunswick, [...].

De resto, tenho me divertido freqüentemente com os pensamentos abstratos e metafísicos da Geometria. Eu descobri um novo método das Tangentes, que fiz imprimir em um jornal de Leipzig. ${ }^{5}$

Para além dessas ocupações, o tema recorrente das discussões era o acalorado debate teológico político que abarcava os problemas da infalibilidade de Deus e da distinção do corpo e da alma, considerações extraídas da filosofia cartesiana e que demandaram o esforço de aperfeiçoamento, dando atenção para os aspectos que não encontraram nas obras de Descartes o acabamento que os decênios que lhe seguiram passaram a demandar da filosofia. De acordo com Arnauld, era necessário

${ }^{5}$ LEIBNIZ, 2004, p. 194. 
avançar com as proposições relativas à Deus, ao mundo e à alma, ultrapassando os domínios da Lógica, pois é preciso satisfazer o entendimento com as demonstrações dessas proposições, ${ }^{6}$ embora o próprio Descartes afirmasse com certa veemência que só conseguiu compreender os fundamentos da Física valendo-se do caminho aberto pela Metafísica para chegar a constatação de que nada de corporal pertence à essência humana.

Arnauld se deteve neste tópico para lembrar ao autor do Discurso e das Meditações que a capacidade de pensar está ligada aos órgãos corporais, e que não apenas a imortalidade das almas racionais pode justificar a distinção tal como propôs Descartes. Estava começando a ganhar expressão uma nova definição de organismo, cujo resultado foi a refutação da velha convicção platonista de que o homem é um espírito que se serve de um corpo. Leibniz e Arnauld refutaram esta concepção tradicional que era ilustrada com a imagem do cavaleiro conduzindo o cavalo, ou do piloto no comando do navio.

A maneira encontrada por Leibniz para superar a ordem lógica foi a consideração da percepção como experiência do entendimento e não algo preso aos sentidos. Em sua correspondência com Arnauld, o filósofo alemão insistiu na importância de se dar atenção às pequenas percepções, ínfimas quando comparadas com a força dos sentidos. A suposição de que a distinção entre o corpo e a alma é real exige a revisão do que se entende por percepção, porque o que está distinto não se encontra separado, ou mesmo compondo as partes que formam um autômato. Em sua Monadologia ${ }^{7}$ Leibniz sugeriu o exemplo do Moinho, comparandoo ao ser dotado de corpo e de alma; as peças do moinho serviriam de

\footnotetext{
${ }^{6}$ Arnauld, em suas objeções às Meditações metafísicas de Descartes, escreveu: “O próprio Senhor Descartes confessa, em suas Respostas às primeiras Objeções, que ele não tem necessidade de uma distinção real, mas que a formal é suficiente, para que uma coisa possa ser conhecida distintamente e separadamente de outra por uma abstração do espírito". (ARNAULD, 1843. p. 4).
}

${ }^{7}$ LEIBNIZ, 2005, p. 149-150, § 17 
termo para a comparação com as capacidades humanas: o pensar, o sentir, o ter percepção. Contudo, estas faculdades mentais não funcionam tal como as engrenagens que fazem rolar a pedra de moer, porque estas são tão só mecanismos materiais e as faculdades da razão não possuem a mesma dinâmica da mecânica.

Arnauld pretendeu explicar a ligação da alma ao corpo com o ato da fecundação, em um escrito no qual se encarregou de refutar as críticas que um autor obscuro endereçou a Descartes. Há o assentimento à tese segundo a qual a alma se une ao corpo na geração da vida, ou dito com precisão, da coincidência entre o pensar e o fazer divino, que quis criar o gênero humano e no mesmo ato volitivo cria "infalivelmente uma alma todas as vezes que se formar um corpo [humano, N.E.] no seio de uma mulher, mesmo que isto ocorra em uma conjunção ilegítima". ${ }^{8}$ Leibniz refutou esta proposição, opondo a existência virtual da alma que chega a atingir, em determinado momento, a condição de alma racional. Nas páginas da Metafísica esta questão foi discutida e os resultados obtidos o colocaram distante da hereditariedade cartesiana.

As ideias de Leibniz relativas à união estável do corpo e da alma seguiram a orientação previamente definida na Monadalogia, que concebeu a simultaneidade da mônada e do universo, ambos criados pelo decreto divino; tudo mais é o resultado da fulguração das substâncias simples geradas, ou as mônadas derivativas da substância simples primeira que é Deus. Nas palavras de Leibniz:

Assim somente Deus é a unidade primitiva, ou a substância simples originária, de onde todas as mônadas criadas ou derivativas são produzidas e nascem, pode-se dizer, por fulgurações contínuas da Divindade de momento em momento, limitada pela receptividade da criatura, a qual é essencialmente limitada. ${ }^{9}$

\footnotetext{
${ }^{8}$ ARNAULD, 1999, p. 102.

${ }^{9}$ LEIBNIZ, 2005, p. 167-168, $§ 47$.
} 
Apenas para recordar, a incumbência que Descartes se propôs, de reformar a ciência, se não o desviou das pesquisas avançadas do seu tempo, ao menos não lhe proporcionou a honra de descobridor do cálculo infinitesimal, do qual estivera muito perto em 1622. As meditações para o estabelecimento do método de investigação da verdade limitaram as considerações sobre o contínuo ${ }^{10}$ no estudo das grandezas de espaço e de tempo. Não é de se estranhar que Descares tenha sido superado por Leibniz, que se deteve na indagação da obra divina, não como físico, mas na condição de metafísico.

Leibnize Arnauld estavam de acordo quanto à condição da união da alma e do corpo. Não se trata de simples agregado de partes distintas, esta certeza é parte do legado cartesiano que concebeu "a correspondência mútua e natural dos pensamentos da alma com os traços do cérebro, e das emoções da alma com os movimentos do espírito", ${ }^{11}$ o que é suficiente, dizia Arnauld, para acreditar que a união da alma e do corpo os fazem juntos e intimamente ligados. Retomando o conteúdo daquele parágrafo da Monadologia citado há pouco, Leibniz deixou para trás a convicção de que a alma surge no ato da fecundação. A explicação do filósofo considera uma realidade maior que a resultante da distinção do corpo e da alma, que em última instância não deixam de dar expressão para o dualismo sem que seja possível superar as diversas objeções que continuamente são feitas à filosofia de Descartes.

Leibniz enfrentou a necessidade de rever o conceito de substância simples e com ele redefiniu a alma e o corpo. Ambos são bem mais que duas substâncias distintas, a substância pensante e a substância extensa; é preciso admitir que estas substâncias são constituídas pela infinidade de substâncias simples que penetram as coisas compostas. O milagre da vida - que seria o momento da fecundação do embrião - era pensado por Leibniz como o momento da "transformação dos viventes preexistentes":

\footnotetext{
${ }^{10}$ FRAGA, 1988, p. 21.

${ }^{11}$ ARNAULD, 1999, p. 92.
} 
Nas sementes dos animais grandes há pequenos animais que, mediante a concepção, adotam um novo revestimento do qual se apropriam, que lhes permite se alimentar e crescer para passar a um teatro maior e realizar a propagação do animal grande. É verdade que as Almas dos animais Espermáticos humanos não são racionais e só chegam a sê-lo quando a concepção destina estes animais à natureza humana. ${ }^{12}$

A posição de Leibniz contrastava com a de Arnauld, que permaneceu fiel à interpretação tradicional das escrituras. $\mathrm{Na}$ correspondência entre os dois filósofos, Leibniz se empenhou enormemente para convencer Arnauld de suas razões. O filósofo alemão advertia o pensador francês da sua subserviência à autoridade de Descartes, ou na predileção pelo pensamento de Santo Agostinho, um traço distintivo do movimento filosófico e religioso inspirado na obra do bispo Cornélio Jansênio. Não obstante às reivindicações de Leibniz, a atitude de Arnauld permaneceu na refutação daquelas proposições que queriam convencêlo de que a explicação da realidade da alma e do corpo só é possível a partir do contínuo que assevera o plano harmônico entre as substâncias e as coisas corpóreas. Arnauld era refratário à definição leibniziana da natureza das formas das substâncias, que, décadas depois, seriam elucidadas na Metafísica. Com essas hipóteses Leibniz afirmava a Arnauld, em carta de 28 de novembro de 1686, que estava perto de "poder decifrar os maiores segredos da natureza universal". ${ }^{13}$

A admissão da novidade de Leibniz implicava no abandono da teoria criacionista fincada na narrativa bíblica. Talvez, mais que os cartesianos, Leibniz tenha levado ao extremo a exortação que Descartes fez aos doutores da Faculdade de Teologia de Paris: de demonstrar a existência de Deus e a distinção do corpo e da alma se servindo da razão natural. Agindo assim é preciso deixar de lado a fábula mosaica da criação

\footnotetext{
${ }^{12}$ LEIBINZ, 2004, p. 157.

${ }^{13}$ LEIBNIZ, 1776, p. 195.
} 
do mundo e do homem, para seguir a direção que a filosofia sugere. $\mathrm{Na}$ nova representação proposta por Leibniz não há mais geração e morte, porque a alma, ou a mônada dominante, não foi gerada naturalmente, ela foi criada pelo decreto divino; portanto, o que não é gerado naturalmente tampouco será consumado naturalmente. Não há, segundo Leibniz, morte em absoluto, o que se constata é um momento em que os animais racionais abandonam aquele teatro maior, mencionado acima, e ingressam em "um teatro mais sutil onde, contudo, podem ser tão sensíveis e estar tão bem regulados como no maior", e conclui:

[...] não só as Almas como também os animais são ingênitos e imperecíveis; são apenas desenvolvidos, envolvidos, revestidos, despojados, transformados; as Almas nunca abandonam totalmente seu corpo e não passam de um corpo a outro inteiramente novo. Não há metempsicose, mas sim metamorfose. ${ }^{14}$

Antes de chegar a esta situação que não encontrou o reconhecimento que merecia, ainda na correspondência com Arnauld e se mantendo na discussão literal do texto mosaico, Leibniz tenta demover o amigo da velha interpretação quando trata da herança de Adão. Foi essa a ocasião para discorrer sobre a teoria dos possíveis, na qual ele trata da realidade do mundo, vendo-a no presente como a configuração do melhor e comportando outras séries possíveis. O melhor é o atual que substancializa, dentre os possíveis, a realidade efetiva, o que prova a bondade e perfeição de Deus, porque ele vê o atual conferindo-lhe todos os predicados que o fazem o melhor dentre todas as séries dos possíveis, não negando a existência virtual dos mundos compossíveis. Eis as linhas da carta de Leibniz a Arnauld datada de 14 de julho de 1686:

Tudo o que é atual pode ser conhecido como possível, e se o Adão atual tiver com o tempo uma bela posteridade, não estará sendo

\footnotetext{
${ }^{14}$ LEIBINZ, 2004, p. 157.
} 
negado este mesmo predicado ao Adão concebido como possível, visto que estais de acordo que Deus enxerga nele todos estes predicados, no momento em que decide criá-lo. ${ }^{15}$

A argumentação de Leibniz livra Deus do jugo da necessidade, em seu lugar é fundamentado o princípio da razão suficiente, pelo qual Deus tem a prerrogativa de escolher dentre todos os possíveis sempre o melhor. O novo princípio é o que garante a liberdade: de Deus e de tudo que existe, inclusive dos animais racionais, "cujas almas se conhece pelo nome de espírito". ${ }^{16}$

Recuperando o que foi dito anteriormente, a filosofia de Leibniz refuta a ideia de morte, porque no universo as mônadas experimentam momentos de evolução e outros tantos de involução, sempre submetidas à justiça divina, que em todos esses momentos faz com que elas estejam sustentadas pela "onipotência, onisciência e bondade soberanas", ${ }^{17}$ e que:

[...] continuem dependendo dele também enquanto existem e operam; e elas recebem continuamente dele aquilo que faz com que possuam alguma perfeição; mas o que lhes resta de imperfeição provém da limitação essencial e original da criatura. ${ }^{18}$

Na ausência da morte é celebrada a vida, característica definitiva que une as filosofias de Leibnize Arnauld, unidos que estavam na crítica a Malebranche e a sua concepção sombria de homem, ${ }^{19}$ de onde prosperou a tendência predominante do humanismo que seria objeto da crítica de

\footnotetext{
${ }^{15}$ LEIBNIZ, 2004, p. 192.

${ }^{16}$ LEIBINZ, 2004, p. 156.

${ }^{17}$ LEIBINZ, 2004, p. 158.

${ }^{18}$ LEIBINZ, 2004, p. 159.

19 “Em si mesmo o homem nada mais é que um puro nada: existe somente porque Deus quer que exista, e se Deus cessasse de querer que o homem existisse, o homem não existiria mais". (MALEBRANCHE, 2003, p. 45).
} 
Nietzsche. Contudo, a filosofia moderna do grande século, a favor da vida, havia rompido, desde então, com o pessimismo, dando a oportunidade de vislumbrar a liberdade humana que concretiza em si o melhor dos possíveis, de todos os planos existenciais, pois o livre arbítrio autoriza a celebração do melhor sempre. ${ }^{20}$ Naquela carta a Arnauld mencionada acima, duas décadas antes da publicação dos últimos escritos, Leibniz já se mostrava convicto da sua bela realização:

Enfim, eu tenho apresentado uma razão decisiva, que a meu ver, tem lugar de demonstração, é o que sempre, em toda proposição afirmativa, verdadeira, necessária ou contingente, universal ou singular, a noção do predicado está compreendida, de alguma maneira naquela do sujeito; predicatum inest subjecto; ou talvez eu não saiba o que seja a verdade. ${ }^{21}$

O que é vivo não faz lembrar apenas coisas distintas; a leitura que Malebranche fez das páginas de Descartes não atentou para o que era sugerido, por isso ele definiu o homem como um nada. Leibniz e Arnauld intuíram algo que ultrapassou a substância simples e as coisas compostas, foi preciso estar atento para o que impede a morte. Somente a potência ultrapassa o corpo e o espírito e dá a oportunidade para tudo existir no universo atualizando os compossíveis de infindáveis mundos, seres e essências. Leibniz, mais do que Arnauld, reconheceu a importância da vida sem limitá-la às formas familiares do humano, vale dizer, sem se restringir ao antropocentrismo. A harmonia preestabelecida aproxima o que está separado, une o que está disperso e sustenta a perenidade do mundo apesar e contra as adversidades. A cultura da vida é maior do que o culto da morte, a vida é mais complexa que o dualismo corpo e alma, tão arraigado às filosofias antropocêntricas.

\footnotetext{
20 “Assim, não há nada de inculto, de estéril, de morto no universo, nem caos, nem confusão, a não ser em aparência”. (LEIBNIZ, 2005, p. 180; § 47).

${ }^{21}$ LEIBNIZ, 1776, p. 193.
} 


\section{REFERÊNCIAS}

ARNAULD, A. Objections contre les Méditations Métaphysiques de René Descartes. In: . Oeuvres philosophiques d'Arnauld. Tome Quatrieme. Paris: Hachette/Ladrange, 1843. p. 1-20.

. Oeuvres de Messire Antoine Arnauld, Docteur de la Maison et Société de Sourbonne. Tome Quatrieme. Paris: S. d'Arnay, 1776.

. Examen du Traité de l'essence du corps contre Descartes. Paris: Fayard, 1999.

BASSETTO, B. F.; MURACHCO, H. G. A pedagogia e a didática de Port-Royal: as escolinhas. In: ARNAULD, A.; LANCELOT, C. Gramática de Port-Royal. Tradução de Bruno F. Bassetto e Henrique G. Murachco. São Paulo: Martins Fontes, 1992. Prefácio, p. 20-30.

FRAGA, G. de. Introdução às Meditações sobre a filosofia primeira. In: DESCARTES, R. Meditações sobe a filosofia primeira. Tradução portuguesa de Gustavo de Fraga. Coimbra: Livraria Almedina, 1988. p. 7-82.

HEGEL. G. W. F. Filosofia da História. Tradução de Maria Rodrigues e Hans Harden. Brasília: Editora UnB, 1995.

LEBRUN, G. Blaise Pascal. São Paulo: Brasiliense, 1983. Coleção Encanto Radical.

LEIBNIZ, G. W. Extrait de diverses lettres de Leibnitz a M. Arnauld et à S. A. S. le Prince Ernest, Landgrave de Hesse-Rhinfels, au sujet de ce Docteur. In: ARNAULD, A. Oeuvres de Messire Antoine Arnauld, Docteur de la Maison et Société de Sourbonne. Tome Quatrieme. Paris: S. d'Arnay, 1776. p. 185-203.

. Discurso de Metafísica. Tradução de Marilena Chaúi. In:

Discurso de Metafisica e outros textos. São Paulo: Martins Fontes, 2004. p. 153-163. 
180 Educação e Filosofia Uberlândia, v. 25, N. Especial, p. 167-180, 2011 - ISSN 0102-6801

. La Monadologie. Paris: Delagrave, 2005.

MALEBRANCHE, N. Brevi meditazioni. Tradução italiana de Alessandro Stile. Soveria Mannelli: Rubbettino, 2003.

PASCAL, B. Pensamentos. Tradução de Sérgio Milliet. In: Pascal. São Paulo: Nova Cultural, 1988. Coleção "Os Pensadores".

Data de registro: $18 / 07 / 2011$

Data de aceite: $24 / 08 / 2011$ 